\title{
The Oxidation of Toluene on Various Molybdenum-Containing Catalysts
}

\author{
N. K. Nag, ${ }^{1}$ T. Fransen, and P. Mars \\ Twente University of Technology, Department of Chemical Technology, P.O. Box 217, Enschede 7500 AE, \\ The Netherlands
}

Received April 11, 1980

\begin{abstract}
The activities for the vapour-phase oxidation of toluene of various molybdenum-containing catalysts have been measured in a flow microreactor operating at 1 atm pressure. The catalysts comprised (a) unsupported crystalline $\mathrm{MoO}_{3}$, (b) $\mathrm{Mo}$ oxide monolayers on $\mathrm{Al}_{2} \mathrm{O}_{3}, \mathrm{CeO}_{2}, \mathrm{TiO}_{2}$, and $\mathrm{ZrO}_{2}$ supports, and (c) $\mathrm{Al}-, \mathrm{Ce}$-, and $\mathrm{Zr}$-molybdate salts. The rates of oxidation of toluene per unit surface area on the monolayer catalysts are higher than those on the corresponding salts, but the selectivities for the partial oxidation products show the opposite trend. The catalytic behaviour of unsupported $\mathrm{MoO}_{3}$ resembles more closely that of the salts than that of the monolayer catalysts. The kinetic data for the oxidation of toluene on all catalysts can be interpreted on the basis of a reduction-oxidation mechanism. The energies of activation for the reduction and oxidation steps are correlated with the ionic potentials of the cations in the supports. Poisoning by pyridine of $\mathrm{MoO}_{x} / \mathrm{TiO}_{2}$ has a profound effect on the activity and selectivity of the monolayer catalyst and gives some information about the nature and concentration of the active sites.
\end{abstract}

\section{INTRODUCTION}

The large influence of foreign ions on the catalytic behaviour of molybdenum oxide is well known. Higher activity and improved selectivity for the partial oxidation of olefins are generally achieved by using $\mathrm{MoO}_{3}$ promoted with $\mathrm{Bi}_{2} \mathrm{O}_{3}$ or $\mathrm{SnO}_{2}$ rather than the pure oxide alone $(1-4)$.

The activities of the catalysts containing molybdenum oxide have been correlated with the rates of isotopic homomolecular and heteromolecular exchange of oxygen (4-7), as well as with the reduction by hydrogen $(2,8)$. The selectivity of these catalysts has been suggested as being connected with the basic $(9)$ and acidic $(3,10)$ properties of the added component or with the different types of metal-oxygen bonds on the surface (11). The selectivity for the partial oxidation products is higher with catalysts containing metal-oxygen double

1 Present address: Fritz-Haber-Institut der MaxPlanck-Gesellschaft zur Förderung der Wissenschaften B. V. Faradayweg 4-6, 1 Berlin 33/Dahlem, Germany. bonds $(12,13)$. Total oxidation is relatively more extensive when this bond is weaker $(6,8,14)$ and predominates with oxides where oxygen is bridged between metal ions.

The purpose of this work has been to study the modifying effect of various metal oxides on the behaviour of molybdenum oxide towards the oxidation of toluene and to establish the influence of these oxides on the rates and activation energies of the oxidation and reduction steps. A systematic comparison has also been made of the catalytic behaviour of the so-called molybdenum oxide monolayer catalysts and of the three-dimensional molybdate salts with that of crystalline $\mathrm{MoO}_{3}$.

\section{EXPERIMENTAL}

\section{Catalysts}

The supports used were either commercial products or were prepared in our laboratory (see Table 1 ).

$\mathrm{CeO}_{2}$ was prepared by heating $\mathrm{Ce}\left(\mathrm{NO}_{3}\right)_{3}$ (E. Merck, Analar) in air at $500^{\circ} \mathrm{C}$ for $2 \mathrm{~h}$ (15). $\mathrm{ZrO}_{2}$ was prepared by precipitation of 
TABLE 1

Summary of the Methods of Preparation and Properties of Various Catalysts

\begin{tabular}{|c|c|c|c|c|c|}
\hline Catalysts & $\begin{array}{l}\text { Source or method } \\
\text { of preparation }\end{array}$ & $\begin{array}{c}\text { Calcination } \\
\text { temperature } \\
\left({ }^{\circ} \mathrm{C}\right)\end{array}$ & $\begin{array}{c}\text { Specific } \\
\text { surface } \\
\text { area } \\
\left(\mathbf{m}^{2} \cdot \mathbf{g}^{-1}\right)\end{array}$ & $\begin{array}{c}\mathrm{MoO}_{3} \text { content } \\
(\mathrm{g} / \mathrm{g}) \times 100\end{array}$ & $\begin{array}{c}\text { Surface area } \\
\text { per } \mathrm{MoO}_{3} \text { unit } \\
\left(\AA^{2}\right)\end{array}$ \\
\hline \multicolumn{6}{|l|}{ 1. Carriers } \\
\hline $\mathrm{CeO}_{2}$ & Ref. (I5) & 500 & 70.0 & & \\
\hline $\mathrm{ZrO}_{2}$ & Ref. (16) & 380 & 125.0 & - & - \\
\hline $\mathrm{TiO}_{2}$ & Degussa $\mathrm{TiO}_{2}$ & - & 47.0 & & \\
\hline $\mathrm{Al}_{2} \mathrm{O}_{3}$ & Degussa $\mathrm{Al}_{2} \mathrm{O}_{3}$ & - & 72.0 & & \\
\hline 2. $\mathrm{MoO}_{3}$ & Ref. (17) & 340 & 3.6 & & \\
\hline \multicolumn{6}{|l|}{$\begin{array}{l}\text { 3. Monolayer } \\
\text { catalysts }\end{array}$} \\
\hline $\mathrm{MoO}_{x} / \mathrm{CeO}_{2}$ & Liquid-phase adsorption & 500 & 67.0 & 8.8 & 18.2 \\
\hline $\mathrm{MoO}_{x} / \mathrm{ZrO}_{2}$ & of molybdate ions on the & 500 & 125.0 & 10.6 & 28.2 \\
\hline $\mathrm{MoO}_{x} / \mathrm{TiO}_{2}$ & support oxides, see Ref. & 500 & 46.0 & 6.1 & 18.0 \\
\hline $\mathrm{MoO}_{x} / \mathrm{Al}_{2} \mathrm{O}_{3}$ & $(I 8)$ for details & 500 & 72.0 & 10.2 & 17.9 \\
\hline \multicolumn{6}{|l|}{ 4. Salts } \\
\hline Al salt I & Prepared by heating an & 530 & 16.5 & 58.4 & \\
\hline Al salt II & intimate mixture of & 600 & 8.0 & 51.5 & \\
\hline Ce salt I & ammonium heptamolybdate & 560 & 2.3 & 39.3 & \\
\hline Ce salt II & and the respective nitrate & 600 & 5.7 & 45.7 & \\
\hline $\mathrm{Zr}$ salt I & (see Experimental & 600 & 5.7 & 55.6 & \\
\hline Zr salt II & Section). & 600 & 0.7 & 55.6 & \\
\hline
\end{tabular}

Note. Salt I prepared by heating mixtures of ammonium heptamolybdate and the respective nitrates. Salt II obtained by steaming salt $\mathrm{I}$ at $600^{\circ} \mathrm{C}$ for several hours.

zirconium hydroxide from a solution of zirconyl nitrate by adding ammonia up to pH 9 (16) and calcining the hydroxide at $380^{\circ} \mathrm{C}$ for $2 \mathrm{~h}$. A high-surface-area sample of $\mathrm{MoO}_{3}$ was prepared by precipitating ammonium molybdate from an aqueous solution of the heptamolybdate by addition of acetone, drying at $100^{\circ} \mathrm{C}$, pressing, and calcining by slowly raising the temperature to $330^{\circ} \mathrm{C}$ in not less than $6 \mathrm{~h}(17)$.

The monolayer catalysts were prepared by adsorption of molybdate ions from an aqueous solution of $1 \%$ ammonium heptamolybdate acidified with nitric acid to $\mathrm{pH} 1$ (18). In each case the support was pressed (generally 20-40 tons $\mathrm{cm}^{-2}$ ) and ground to particles of a diameter between 0.3 and 0.5 $\mathrm{mm}$. These catalysts will be referred to as $\mathrm{MoO}_{x} / \mathrm{Al}_{2} \mathrm{O}_{3}$, etc.

The salts were prepared by heating a mixture of ammonium heptamolybdate and the respective metal nitrates. The results and a summary of the methods of preparation are given in Table 1 . The salt thus obtained is designated as "salt I" which, when treated with steam at $600^{\circ} \mathrm{C}$ for several hours, gives "salt II."

\section{Apparatus}

A fixed-bed flow reactor operating at atmospheric pressure was used to study the reaction. The reactor consisted of a quartz U-tube $(50 \mathrm{~cm}$ long, $0.5 \mathrm{~cm}$ i.d.) with a sintered quartz disc at the lower end of one limb upon which the catalyst was placed. In order to avoid adverse thermal effects the catalysts $(0.25 \mathrm{~g})$ were diluted with about two volumes of inert quartz of the same particle size (i.e., $0.3-0.6 \mathrm{~mm}$ ). The height of the catalyst bed varied between 3 and 5 $\mathrm{mm}$ depending on the sample. The reactor was placed vertically inside a tubular fur- 
nace heated electrically and controlled within $\pm 1^{\circ} \mathrm{C}$. The reactor was continuously fed with toluene vapour generated by passing $\mathrm{He}$ or a $\mathrm{He}-\mathrm{O}_{2}$ mixture through two saturators in series, one at room temperature and the other at $-3.5^{\circ} \mathrm{C}$.

Poisoning experiments were carried out by introducing pulses of 0.2 to $2.0 \mu \mathrm{l}$ of pyridine into the reactant gas stream. The conversion $^{2}$ and selectivity ${ }^{3}$ were measured as a function of time, temperature, and partial pressure of oxygen.

\section{Analysis}

A Becker gas chromatograph equipped with a flame ionization detector was used for the determination of benzene, toluene, and benzaldehyde. The glc column consisted of a 2-m-long copper tube ( $2 \mathrm{~mm}$ i.d.) packed with $5 \%$ Apiezon L on Chromosorb wax and operated with $\mathrm{He}(50 \mathrm{ml} / \mathrm{min})$ as the carrier gas at $155^{\circ} \mathrm{C}$. Since benzoic acid could not be separated by this arrangement it was estimated from the carbon balance. This is justified by the fact that under no circumstances was any carbon loss by coke formation observed and benzoic acid was the only oxidation product which could not be determined. $\mathrm{CO}_{2}$ was estimated by a nonaqueous titration method (19). Draeger tubes were used for the detection of carbon monoxide.

The molybdenum contents of the catalysts were determined by X-ray fluorescence spectroscopy. The surface areas of the samples were measured with an automatic BET apparatus. Argon $\left(\phi=13.8 \AA^{2}\right)$ was used as the adsorbate at liquid nitrogen temperature.

\section{RESULTS}

\section{Catalyst Preparation}

In Table 1 the conditions for salt forma-

\footnotetext{
${ }^{2}$ Conversion $(\%)=($ No. of moles of toluene oxidized $\times 100) / \mathrm{No}$. of moles of toluene passed.

${ }^{3}$ Selectivity $(\%)=$ No. of moles of particular product formed $\times 100$ ) $/ \mathrm{No}$. of moles of toluene converted.
}

tion and some properties of all catalysts are given. In the case of monolayer catalysts, the amounts of molybdenum oxide maximally adsorbed on the supports were normally found to be proportional to their surface areas which remained virtually unaltered by the adsorption of molybdenum oxide (see Table 1). Preparation of salts by heating the respective oxides above $700^{\circ} \mathrm{C}$ ensures purity (i.e., freedom from $\mathrm{MoO}_{3}$ ), but only with almost total loss of surface area. Consequently, the molybdate salts were prepared as pure as possible and at such a temperature that a reasonable surface area was still retained. However, the XRD data of these salts showed the presence of some crystallites of $\mathrm{MoO}_{3}$. Therefore, the catalytic activities were also measured of salts which were completely free from $\mathrm{MoO}_{3}$ crystals (as indicated by XRD data) by steaming at $600^{\circ} \mathrm{C}$. Títanium molybdate could not be prepared by heating a mixture of titanium nitrate and ammonium heptamolybdate, in agreement with the findings of Doyle et al. (20).

\section{Activity and Selectivity}

The conversion of toluene to different products, except for benzaldehyde in the case of $\mathrm{MoO}_{x} / \mathrm{CeO}_{2}$ and $\mathrm{MoO}_{x} / \mathrm{ZrO}_{2}$, decreases during approximately the first half hour. This is true for all molybdenum-containing catalysts. The steady state is reached within $40 \mathrm{~min}$. No decrease in the activity has been observed thereafter up to at least $30 \mathrm{~h}$. All kinetic data were taken under steady-state conditions. Low conversions of the reactants (toluene: $<20 \%$, oxygen: $<9 \%$ ) enabled the reactor to be considered as working differentially.

The areal activities (i.e., toluene conversion per square meter per unit of time) and selectivities of various monolayer catalysts have been plotted as a function of temperature in Figs. 1 and 2. The order of activities is reflected by the temperature range necessary to obtain a few percent conversion (see Table 2). The general trend is that activities decrease in the order: support 

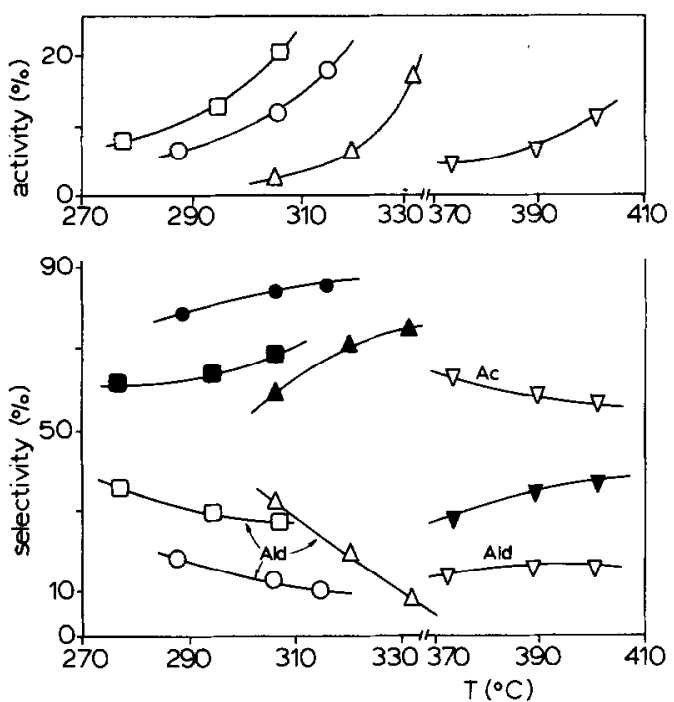

FIG. 1. Activities and selectivities for the toluene oxidation of some molybdenum oxide monolayer catalysts and of $\mathrm{Al}$-molybdate salt as a function of temperature. (口) $\mathrm{MoO}_{x} / \mathrm{CeO}_{2} ;$ (O) $\mathrm{MoO}_{x} / \mathrm{TiO}_{2} ;(\triangle)$ $\mathrm{MoO}_{x} / \mathrm{Al}_{2} \mathrm{O}_{3} ;(\nabla) \mathrm{Al}$-molybdate. $\mathrm{Ald}=$ benzaldehyde; $\mathrm{Ac}=$ benzoic acid; black points $=$ total oxidation.

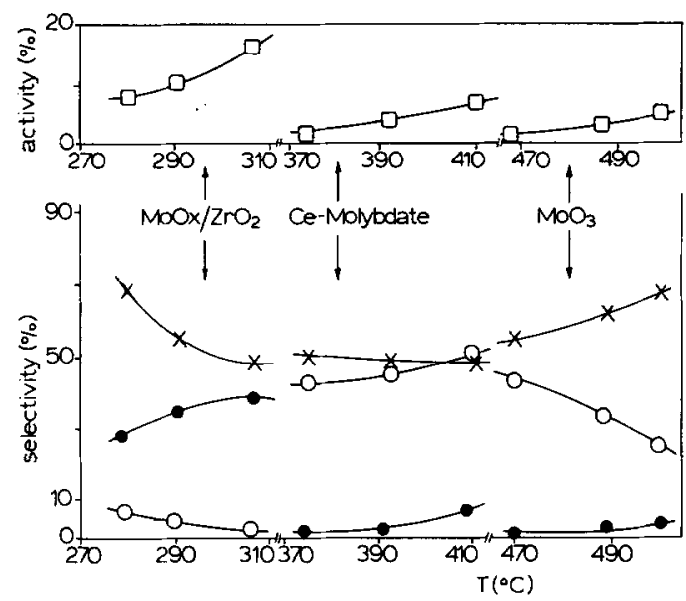

FIG. 2. Activities and selectivities for the toluene oxidation on $\mathrm{MoO}_{s} / \mathrm{ZrO}_{2}$, Ce molybdate and crystalline $\mathrm{MoO}_{3}$ as a function of temperature. ( $\square$ ) Conversion per $\mathrm{m}^{2} ;(O)$ benzaldehyde; $(X)$ benzoic acid; $(O)$ total oxidation to $\mathrm{CO}_{2}$.

oxides $\geq$ monolayer catalysts $>$ salts $>$ crystalline $\mathrm{MoO}_{3}$. In addition to the detailed information on the selectivities in

TABLE 2

Oxidation of Toluene, Activity Level, and Product Distribution of Various Catalysts

\begin{tabular}{|c|c|c|c|c|c|}
\hline \multirow[t]{2}{*}{ Catalyst } & \multirow{2}{*}{$\begin{array}{c}\text { Temp. range }{ }^{a} \\
\left({ }^{\circ} \mathrm{C}\right)\end{array}$} & \multicolumn{4}{|c|}{ Product Distribution } \\
\hline & & $\mathrm{C}_{6} \mathrm{H}_{5} \mathrm{CHO}$ & $\mathrm{C}_{6} \mathrm{H}_{5} \mathrm{COOH}$ & $\mathrm{C}_{6} \mathrm{H}_{6}$ & $\mathrm{CO}_{2}$ \\
\hline \multicolumn{6}{|c|}{ 1. Monolayer catalysts } \\
\hline $\mathrm{MoO}_{x} / \mathrm{CeO}_{2}$ & $275-306$ & + & -- & -- & ++ \\
\hline $\mathrm{MoO}_{x} / \mathrm{ZrO}_{2}$ & $279-306$ & - & ++ & -- & + \\
\hline $\mathrm{MoO}_{x} / \mathrm{TiO}_{2}$ & $288-315$ & + & - & -- & $+t$ \\
\hline $\mathrm{MoO}_{x} / \mathrm{Al}_{2} \mathrm{O}_{3}$ & $306-336$ & + & - & - & ++ \\
\hline \multicolumn{6}{|l|}{ 2. Salts } \\
\hline Al salt II & $374-401$ & + & ++ & - & + \\
\hline Ce salt I & $374-410$ & + & + & - & - \\
\hline Ce salt II & $425-454$ & ++ & + & - & - \\
\hline $\mathrm{Zr}$ salt II & 374 & + & ++ & - & + \\
\hline \multicolumn{6}{|l|}{ 3. Pure oxides } \\
\hline $\mathrm{CeO}_{2}$ & Up to 340 & nil & nil & nil & +++ \\
\hline $\mathrm{Al}_{2} \mathrm{O}_{3}$ & Up to 400 & nil & nil & nil & +++ \\
\hline $\mathrm{TiO}_{2}$ & $306-333$ & nil & nil & nil & +++ \\
\hline $\mathrm{ZrO}_{2}$ & $336-375$ & nil & nil & - & +++ \\
\hline $\mathrm{MoO}_{3}$ & $468-500$ & + & ++ & - & - \\
\hline
\end{tabular}

Note. +++ practically complete oxidation to $\mathrm{CO}_{2},>80 \%$ selectivity; ++ major product, $50-80 \%$ selectivity; + minor product, $10-50 \%$ selectivity; - small amount, $1-10 \%$ selectivity; -- trace amount, $<1 \%$ selectivity.

a Temperature necessary for the conversion of 3-10\% of toluene, when $60 \mathrm{~cm}^{3} \mathrm{~min}^{-1}$ are led over $0.25 \mathrm{~g}$ catalyst; $P_{\mathrm{O}_{2}}=0.166 \mathrm{~atm} ; \boldsymbol{P}_{\mathrm{t}}=7.1 .10^{-3} \mathrm{~atm}$. 
Figs. 1 and 2, a general survey of the product distribution is given in Table 2 . With respect to both activity and selectivity, crystalline $\mathrm{MoO}_{3}$ resembles the salts more than the monolayer catalysts. This similarity is not, however, due to the presence of traces of $\mathrm{MoO}_{3}$ crystals left on the salts, as is apparent by inspecting the behaviour of the steam-treated salts. Although the catalytic activities of the salts were lowered to some extent by treatment with steam at $600^{\circ} \mathrm{C}$, the selectivities hardly changed.

The colour of the monolayer catalysts changed from light yellow to dark blue when the oxygen/toluene ratio was decreased from 23 to 4 . The dark colour is indicative of Mo ions with a valency lower than 6 and not of coking products, because the treatment of the dark catalysts with oxygen did not yield any oxides of carbon. The colour of the salts, however, was not found to depend on the oxygen/toluene ratio.

A decrease of the oxygen/toluene ratio, as mentioned above, also causes a minor change in the selectivity of the catalysts. For example, the selectivities of $\mathrm{MoO}_{x} / \mathrm{Al}_{2} \mathrm{O}_{3}$ and $\mathrm{MoO}_{x} / \mathrm{TiO}_{2}$ at $306^{\circ} \mathrm{C}$ towards benzaldehyde are larger at higher oxygen/toluene ratios.

\section{Poisoning Experiments}

These experiments show that a pulse of pyridine at the steady state of toluene oxidation on $\mathrm{MoO}_{x} / \mathrm{TiO}_{2}$ causes a sudden decrease in the conversion (Fig. 3). This poisoning is reversible because the decreased conversion increases with time and attains nearly the original value about $25 \mathrm{~min}$ after the injection of pyridine. In the poisoned condition, the selectivity for benzaldehyde formation increases to a very high value at the expense of the total oxidation. Figure 3 clearly demonstrates the effect of adsorbed pyridine on the activity and selectivity of a representative molybdenum oxide monolayer catalyst.

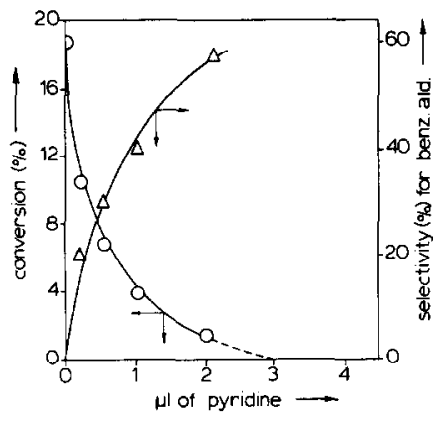

FIG. 3. Activities and selectivities for toluene oxidation on $\mathrm{MoO}_{x} / \mathrm{TiO}_{2}$ cataly st at $360^{\circ} \mathrm{C}$ after poisoning with various amounts of pyridine. Measurements were made 2 min after pyridine injection.

\section{DISCUSSION}

\section{Preparation of the Catalysts}

The amount of Mo oxide maximally adsorbed per unit surface area of $\mathrm{CeO}_{2}, \mathrm{TiO}_{2}$, and $\mathrm{Al}_{2} \mathrm{O}_{3}$ from aqueous solutions corresponds well with those reported earlier in the literature $(18,21)$. Its reciprocal, that is, the area available per $\mathrm{Mo}^{6+}$ oxide unit, corresponds to the mean cross-sectional area of a $\mathrm{Mo}^{6+}$ oxide unit in crystalline $\mathrm{MoO}_{3}\left(15.4 \AA^{2}\right)$ (Table 1). This indicates that under the conditions of their formation a practically complete monolayer of Mo oxide is present on the surface of these supports (21). The slightly different behaviour of $\mathrm{ZrO}_{2}$ might be due to the presence of micropores (16) which are not easily penetrated by the Mo anions during the adsorption stage of preparation.

A suitable method was found for the preparation of $\mathrm{Al}$ and $\mathrm{Ce}$ salts with a workable surface area and a reasonable purity. Table 1 shows the results. The excess $\mathrm{MoO}_{3}$ crystals were removed from the freshly prepared salts by steaming at $600^{\circ} \mathrm{C}$ for several hours.

\section{Activities of the Catalysts}

The supports, which are almost exclusively nonselective, influence both the activity and selectivity of $\mathrm{MoO}_{3}$, which, in turn, masks or modifies the catalytic properties of the supports. The suppression of 
the highly nonselective oxidation property of $\mathrm{CeO}_{2}$ due to the presence of a monolayer of Mo oxide on the surface is in accord with the property of the Ce-molybdate salt, which also is a highly selective catalyst for the formation of benzaldehyde and benzoic acid (Table 2). Similar behaviour is observed with other monolayer catalysts and salts. Akimoto and Echigoya $(13,22)$ and Trifirò and Pasquon (12) observed that nonselective oxidation occurs more easily on oxides containing bridged ( $\sigma$-bonded) oxygen than on double-bonded ( $\pi$-bonded) oxygen of more acidic oxides. The present findings substantiate this. The activity and selectivity patterns, therefore, indicate the presence of only a small amount of support oxide units with bridged oxygen on the surface of the monolayer catalysts and an even smaller amount of these units on the surface of the salts. It is also clear from these results that the more active catalysts are more conducive to the total oxidation of toluene. The activity trend, supports $\geq$. monolayer catalysts $>$ salts $>\mathrm{MoO}_{3}$, is exactly opposite to the selectivity trend.

\section{Kinetics}

The change in colour of the monolayer catalysts associated with decreased oxygen/toluene ratio and the ability of the fresh catalysts to oxidize toluene in the absence of gaseous oxygen indicate that the reaction proceeds via the consumption of lattice oxygen of the surface and reoxidation of the reduced sites. Therefore, the rate equation, based on the assumption of a redox mechanism (23), was applied to the rate data, namely,

$$
r^{-1}=\frac{\alpha}{k_{0} P_{0_{2}}{ }^{n}}+\frac{1}{k_{\mathrm{r}} P_{\mathrm{t}}{ }^{m}},
$$

where $r$ is the reaction rate (moles of toluene $\left.\min ^{-1} \mathrm{~m}^{-2}\right), k_{0}$ and $k_{\mathrm{r}}$ are the rate constants for the oxidation of the reduced sites and for the reduction of the oxidized sites, $P_{\mathrm{O}_{2}}$ and $\boldsymbol{P}_{\mathrm{t}}$ are the partial pressures of oxygen and toluene (atm), $n$ and $m$ are the reaction orders, $\alpha$ is the average num- ber of oxygen molecules consumed in oxidizing one molecule of toluene to the various products. The linearized equation with $n=m=1$,

$$
\frac{P_{\mathrm{O}_{2}}}{r}=\frac{\alpha}{k_{\mathrm{o}}}+\frac{P_{\mathrm{O}_{2}}}{k_{\mathrm{r}} P_{\mathrm{t}}}
$$

was found to be applicable to the rate data of all catalysts. The values of $\alpha$ have been calculated from the product distribution and are between 4.0 and 8.1 for the monolayer catalysts, 9.0 for the supports, about 2.5 for $\mathrm{MoO}_{3}$, and between 2.2 and 4.9 for the salts. Figure 4 demonstrates the applicability of this equation to the rate data. The kinetic parameters were calculated from Arrhenius plots and are given in Table 3 .

A change in catalyst composition leads to two important observations relative to the kinetic parameters, namely, (a) an inverse relation between the values of $E_{0}$ and $E_{\mathrm{r}}$ and (b) a strong compensation effect between $E_{0}$ and $A_{\mathrm{o}}$ and between $E_{\mathrm{r}}$ and $A_{\mathrm{r}}\left(A_{\mathrm{o}}\right.$ and $A_{\mathrm{r}}$

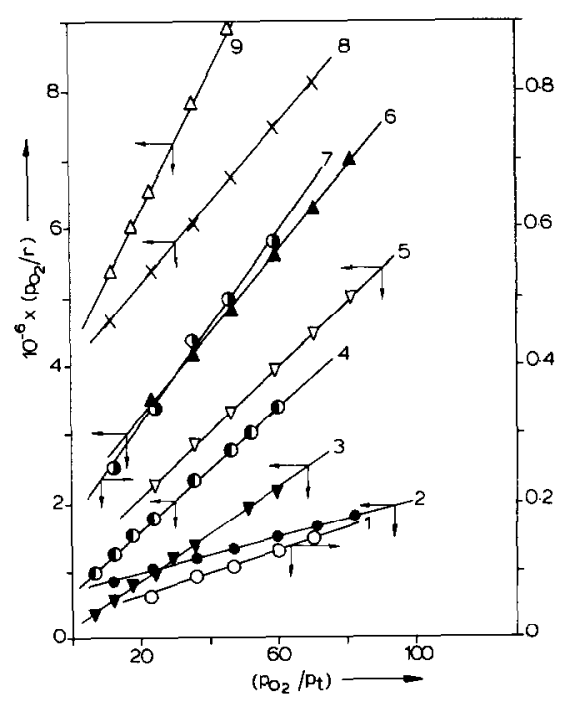

FIG. 4. Demonstration of the validity of rate equation (2) for toluene oxidation. $P_{\mathrm{t}}=0.007 \mathrm{~atm}, 0.04<$ $P_{\mathrm{O}_{2}}<0.7 \mathrm{~atm}$. Rates are expressed in moles $\mathrm{min}^{-1} \mathrm{~m}^{-2}$. 1. Ce salt I at $410^{\circ} \mathrm{C} ; 2 . \mathrm{MoO}_{r} / \mathrm{TiO}_{2}$ at $306^{\circ} \mathrm{C} ; 3 . \mathrm{MoO}_{r} /$ $\mathrm{CeO}_{2}$ at $306^{\circ} \mathrm{C} ; 4 . \mathrm{MoO}_{x} / \mathrm{ZrO}_{2}$ at $306^{\circ} \mathrm{C} ; 5 . \mathrm{TiO}_{2}$ at $306^{\circ} \mathrm{C} ; 6$. Al salt II at $374^{\circ} \mathrm{C} ; 7$. Ce salt II at $454^{\circ} \mathrm{C} ; 8$. $\mathrm{ZrO}_{2}$ at $350^{\circ} \mathrm{C} ; 9$. $\mathrm{MuO}_{x} / \mathrm{Al}_{2} \mathrm{O}_{3}$ at $306^{\circ} \mathrm{C}$. 
TABLE 3

Activation Energies and Preexponential Factors of the Oxidation and the Reduction Steps of Toluene Oxidation on Various Catalysts

\begin{tabular}{|c|c|c|c|c|}
\hline Catalyst & $\begin{array}{c}E_{\mathrm{o}} \\
\left(\mathrm{kJ} \cdot \mathrm{mole}^{-1}\right)\end{array}$ & $\begin{array}{c}E_{\mathrm{r}} \\
\left(\mathrm{kJ} \cdot \mathrm{mole}^{-1}\right)\end{array}$ & $\begin{array}{c}A_{0} \\
\left(\text { Mole } \cdot \mathrm{min}^{-1} \cdot \mathrm{m}^{-2} \cdot \mathrm{atm}^{-1}\right)\end{array}$ & $\underset{\left(\mathrm{mole} \cdot \mathrm{min}^{-1} \cdot \mathrm{m}_{\mathrm{r}}\right.}{\left.\stackrel{-2}{\mathrm{~atm}^{-1}}\right)}$ \\
\hline $\mathrm{MoO}_{x} / \mathrm{CeO}_{2}$ & 168.4 & 74.3 & $1.8 \times 10^{7}$ & $3.1 \times 10^{2}$ \\
\hline $\mathrm{MoO}_{x} / \mathrm{ZrO}_{2}$ & 120.5 & 128.5 & $7.1 \times 10^{3}$ & $1.0 \times 10^{2}$ \\
\hline $\mathrm{MoO}_{x} \mathrm{TiO}_{2}$ & 93.7 & 180.2 & $5.6 \times 10^{1}$ & $1.8 \times 10^{9}$ \\
\hline $\mathrm{MoO}_{x} / \mathrm{Al}_{2} \mathrm{O}_{3}$ & 80.6 & 187.7 & $3.1 \times 10^{1}$ & $6.3 \times 10^{7}$ \\
\hline Ce salt I & 153.3 & 81.5 & $2.0 \times 10^{6}$ & $2.2 \times 10^{4}$ \\
\hline Ce salt II & 229.8 & 120.1 & $2.0 \times 10^{11}$ & $1.4 \times 10^{5}$ \\
\hline Al salt II & 121.0 & 121.0 & $8.9 \times 10^{5}$ & $8.9 \times 10^{3}$ \\
\hline Pure $\mathrm{TiO}_{2}$ & 50.0 & 160.9 & $6.3 \times 10^{0}$ & $7.8 \times 10^{8}$ \\
\hline Pure $\mathrm{ZrO}_{2}$ & 121.0 & 49.1 & $1.0 \times 10^{3}$ & $1.0 \times 10^{-3}$ \\
\hline $\mathrm{MoO}_{3}$ & 210.7 & 62.2 & $1.0 \times 10^{7}$ & $3.1 \times 10^{5}$ \\
\hline
\end{tabular}

are the preexponential factors in the Arrhenius equation.)

(a) This observation may have the background that an increase in the binding energy between the active oxygen and the Mo ion hinders the removal (reflected by the higher value of $E_{\mathrm{r}}$ ) of the former by toluene and facilitates (shown by a lower value of $\left.E_{\mathrm{o}}\right)$ the uptake of oxygen by the reduced catalyst.

There is also a correlation of $E_{0}$ and $E_{\mathrm{r}}$ with the ionic potential, $z / r$, (i.e., the ratio of charge and radius) of the support cations of the monolayer catalysts (Fig. 5). This means that high-valent and small-sized support cations cause an increase in $E_{\mathrm{r}}$ for the

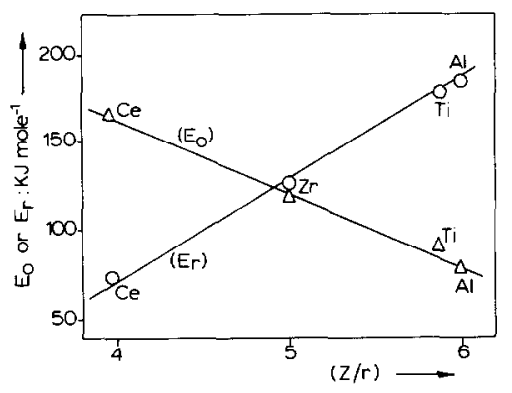

FIG. 5. Correlations of the activation energies of the oxidation $\left(E_{0}\right)$ and reduction $\left(E_{\mathrm{r}}\right)$ steps of toluene oxidation on the various molybdenum oxide monolayer catalysts with the ionic potentials of the respective support ions (using Pauling ionic radii). oxidation of toluene on the molybdenum oxide monolayer catalysts. The reaction mechanism assumed for this type of composite catalyst embodies the adsorption of toluene and abstraction of a $\mathrm{H}$ atom from the methyl group by an acid site and attachment of the benzyl radical to a basic site $(3,14,24,25)$. This adsorbed benzyl radical is subsequently oxidized partially or totally depending upon the nature of the catalyst. From a theoretical point of view, as well as from the experimental observations of Sachtler et al. (26), the value of $E_{\mathrm{r}}$ can be inversely correlated with $\mathrm{Mo}=\mathrm{O}$ bond strength. All the above information suggests, therefore, that the bond strength of the active oxygen on the molybdenum oxide monolayer catalysts increases with increasing ionic potential of the cations of the supporting oxides.

(b) The compensation effect is illustrated in Fig. 6 for all the catalysts used. Mann (27) observed the same effect with various oxidation and isotope exchange reactions on doped and undoped vanadium oxide catalysts. The wide difference in the values of $A_{o}$ and $A_{r}$, as observed from Table 3, cannot stem primarily from the changes in the entropies of activation and reaction entropies of the established equilibria (28). The large change in the ratio of the values 


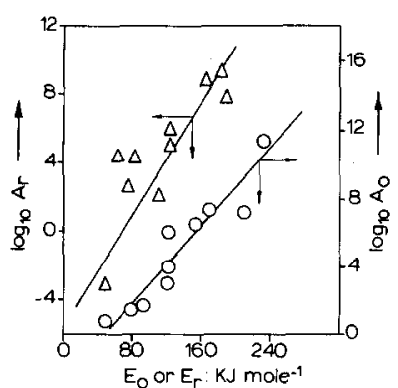

FIG. 6. The compensation effect of the oxidation $(O)$ and reduction $(\triangle)$ steps of the oxidation of toluene. $A_{0}$ and $A_{\mathrm{r}}$ are expressed in moles $\mathrm{min}^{-1} \mathrm{~m}^{-2}$ atm ${ }^{-1}$. The correlation coefficients with respect to the oxidation and reduction steps are +0.93 and +0.79 , respectively.

of $A_{\mathrm{o}}$ and $A_{\mathrm{r}}$ with different catalysts suggests that molecular oxygen, during the reoxidation step of the redox cycle, does not adsorb directly on all anion vacancies (29) created by toluene during its oxidation. This means, therefore, that toluene reacts (at least partly) with $\mathrm{Mo}=\mathrm{O}$ sites which are not directly oxidized by gaseous oxygen during the reoxidation step of the reduced catalyst pertaining to the redox mechanism.

The results of poisoning experiments with pyridine give some idea of the nature and concentration of the active sites on the molybdenum oxide monolayer catalysts. Total, albeit transient, loss of activity of $\mathrm{MoO}_{x} / \mathrm{TiO}_{2}$ seems to take place by the adsorption of about $3 \mu$ lof pyridine on 0.25 $\mathrm{g}$ of the catalyst (Fig. 3). This corresponds to a pyridine/Mo ratio of about 0.3 and suggests that for the monolayer catalysts the number of active sites is approximately one-third of the number of Mo ions present of the surface.

\section{The Selectivities of the Catalysts}

The relative rate of the formation of $\mathrm{CO}_{2}$ on the supports is much higher than on the molybdenum oxide monolayer catalysts and is practically negligible on crystalline $\mathrm{MoO}_{3}$ and most of the salts. The nearly identical behaviour of the salts and crystalline $\mathrm{MoO}_{3}$ (see Table 2) suggests that either the activity and selectivity of the salts are mainly due to the $\mathrm{MoO}_{3}$ crystals present on the surface or alternatively, that the species formed on the surface of the salts by the interaction of $\mathrm{Mo}=\mathrm{O}$ and the support oxide units have similar catalytic properties to crystalline $\mathrm{MoO}_{3}$. Since it has already been seen from the behaviour of steamed and unsteamed salts that this similarity is not due to the excess $\mathrm{MoO}_{3}$ crystals on the surface, the second explanation is preferred.

The oxidation properties of the monolayer catalysts and the salts demonstrate an inverse relationship between activity and selectivity. This kind of phenomenon has also been reported in the literature (5). It is noteworthy that the selective properties neither of the monolayer catalysts nor of the salts are a function of the foreign ion.

The increase in selectivity for the production of benzaldehyde at the expense of $\mathrm{CO}_{2}$ (Fig. 6) on a pyridine-poisoned monolayer catalyst is in harmony with the observation of Akimoto and Echigoya (22) that the total oxidation of butadiene on a pyridine-poisoned $\mathrm{MoO}_{3}$ catalyst supported on $\mathrm{Al}_{2} \mathrm{O}_{3}$ diminishes considerably as compared with the unpoisoned catalyst. It is also known that the total oxidation of aromatic hydrocarbons on vanadium-oxide-containing catalysts is suppressed by the presence of traces of alkali metal ions. Therefore, the general conclusion is that the total oxidation (to $\mathrm{CO}_{2}$ ) is connected with relatively strong acid sites. Obviously, their strength would decide whether oxygen should attack the methyl group or the aromatic nucleus to yield predominant amounts of partial oxidation products or $\mathrm{CO}_{2}$, respectively.

\section{CONCLUSIONS}

1. The activities of the various groups of catalysts reported here for the oxidation of toluene decrease in the order: support oxides $\geq$ molybdenum oxide monolayer catalysts $>$ molybdate salts $>$ crystalline molybdenum oxide. The selectivities for partial oxidation products follow exactly the opposite trend. 
2. A relatively small number of support oxide units (with $\sigma$-bonded bridged oxygen) appear to be present on the surface of the molybdenum oxide monolayer catalysts and an even smaller number on the molybdate salts.

3. The bond strength of the active oxygen units on the monolayer catalysts increase with increasing ionic potential of the support oxide upon which the molybdenum oxide monolayers are formed.

4. There is a strong indication that the oxidation of the reduced active sites does not occur by the direct attack of gaseous oxygen on the sites during the reoxidation step.

5. The total oxidation of toluene to $\mathrm{CO}_{2}$ occurs on relatively strong acid sites on the catalyst surface.

6. The number of active sites on the molybdenum oxide monolayer catalysts is approximately one-third of the number of Mo ions present on the surface.

\section{ACKNOWLEDGMENTS}

One of us (N. K. Nag) thanks the Akzo-Chemie Netherlands B. V. and the Twente University for a fellowship during 1976. Thanks are also due to J. Boeijsma and F. Roozeboom for their assistance in some of the experimental work, and to P. J. Gellings for his comments.

\section{REFERENCES}

1. Buiten, J., J. Catal. 21, 188 (1968).

2. Tan, S., Moro-oka, Y., and Ozaki, A., J. Catal. 17, 125 and 132 (1970).

3. Ai, M., and Ikawa, T., J. Catal. 40, 203 (1975).

4. Batist, Ph. A., Der Kinderen, A. H. W. M., Leeuwenburgh, Y., Metz, F. A. M. G., and Schuit, G. C. A., J. Catal. 12, 45 (1968).

5. Boreskov, G. K., in "Proceedings, 3rd International Congress on Catalysis, Amsterdam, 1964," p. 163. North-Holland, Amsterdam, 1965.

6. Gelbshetin, A. J., Stroeva, S. S., Bakshi, Yu. M., and Mischenko, Yu. A., in "Proceedings, 4th International Congress on Catalysis, Moscow, 1968' (B. A. Kazansky, Ed.), Vol. I, p. 297. Akadémiai Kiadó, Budapest, 1971.

7. Boreskov, G. K., in "Advances in Catalysis and
Related Subjects," Vol. 15, p. 309. Academic Press. New York/London, 1965.

8. Sachtler, W. H. M., and De Boer, N. H., in "Proceedings, 3rd International Congress on $\mathrm{Ca}$ talysis, Amsterdam, 1964," p. 252. North-Holland, Amsterdam, 1965.

9. Baryshevskay, I. M., and Gorokhavahlis, B., React. Kinet. Catal. Lett. 5, 337 (1976).

10. Pernicone, N., Liberti, G., and Ersini, L., in "Proceedings, 4th International Congress on $\mathrm{Ca}$ talysis Moscow, 1968" (B. A. Kazansky, Ed.), Vol. I, p. 287. Akadémiai Kiadó, Budapest, 1971.

11. Cornaz, P. F., Van Hooff, J. H. C., Pluym, F. J., and Schuit, G. C. A., Discuss. Faraday Soc. 41, 290 (1966).

12. Trifirò, F., and Pasquon, I., J. Catal. 12, 412 (1968).

13. Akimoto, M., and Echigoya, E., J. Catal. 29, 191 (1973).

14. Haber, J., and Grzybowska, B., J. Catal. 28, 489 (1973).

15. Potman, W., Van Ommen, J. G., and Dahmen, E. A. M. F., Mikrochim. Acta (Wien) I, 633 (1975).

16. Rijnten, H. Th., in "Physical and Chemical Aspects of Adsorbents and Catalysts" (B. C. Linsen, Ed.). Academic Press, London/New York, 1970.

17. Fransen, T., Van Berge, P. C., and Mars, P., React. Kinet. Catal. Lett. 5, 445 (1976).

18. Sonnemans, J., and Mars, P., J. Catal. 31, 209 (1973).

19. Jones, R. F., Gale, P., Hopkins, P., and Powell, L. N., Analyst 90, 623 (1965).

20. Doyle, W. P., McGuire, G., and Clark, G. M., J. Inorg. Nucl. Chem. 28, 1185 (1966).

21. Fransen, T., Van Berge, P. C., and Mars, P., in "Preparation of Catalysts" (B. Delmon, P. A. Jacobs, and G. Poncelet, Eds.), p. 405. Elsevier, Amsterdam, 1976.

22. Akimoto, M., and Echigoya, E., J. Catal. 31, 278 (1973)

23. Mars, P., and Van Krevelen, D. W., Chem. Eng. Sci. Suppl. 3, 41 (1954).

24. Godin, G. W., McLain, C. C., and Porter, E. H., in "Proceedings, 4th International Congress on Catalysis Moscow, 1968," Vol. I, p. 271. Akadémiai Kiadó, Budapest, 1971.

25. Sachtler, W. M. H., Catal. Rev. Sci. Eng. 4, 27 (1968).

26. Sachtler, W. H. M., Dorgelo, G. J. H., Fahrenfort, J., and Voorhoeve, R. J. H., Recueil 89, 460 (1970).

27. Mann, R. F., Canad. J. Chem. 49, 1520 (1971).

28. Baetzold, R. C., and Somorjai, G. A., J. Catal. 45, 94 (1976).

29. Keulks, G. W., J. Catal. 19, 232 (1970) 